\title{
HEIGHT AND ATTITUDE CONTROL OF A QUADROTOR UAV VIA DISCRETE-TIME BACKSTEPPING
}

\author{
Fatih ADIGÜZEL ${ }^{1, *}$ id , Tarık Veli MUMCU ${ }^{1}$ \\ ${ }^{1}$ Department of Electrical and Electronics Engineering, Istanbul University-Cerrahpasa, Istanbul, Turkey
}

\begin{abstract}
In this study, we focus on control of height and attitude of an unmanned aerial vehicle quadrotor via a backstepping control method in the discrete-time setting. Firstly, the mathematical model of the quadrotor unmanned aerial vehicle is introduced and the mathematical system equations are evaluated to discretize with the standard Euler method. Afterward, the designed backstepping control has been considered in one structure that derives the outputs of height and attitude subsystems to desired trajectories, respectively. Then, the proposed discrete-time backstepping controllers have individually shown the stability of the closed-loop system for z position and roll, pitch, yaw angle dynamics the sense of Lyapunov and by Barbalat's lemma. In order to show the effectiveness of the obtained controllers for height and attitude subsystems, computer simulation studies have been presented by being compared with the traditional control method PD and satisfactory results have been obtained.
\end{abstract}

Keywords: Backstepping control; Discrete Control, Attitude control; Height control; Quadrotor

\section{INTRODUCTION}

Unmanned Aerial Vehicles (UAV) are fully autonomous motorized aircraft. They are used in various fields [1-4] such as military, entertainment, illumination, transportation. Their importance has gained extra credits in missions where it is too dangerous to deploy the task with a human on board, concurrently it is important not to have any human faults, errors. For UAVs, one can speak about two main classes to work on: multirotor [5] or fixed-wing [6]. These two have different advantageous one over another, however, in recent years it is also possible to see hybrid vehicles where edges of these two classes are embedded onto the same vehicle. Among multirotor, quadrotors have become very popular due to numerous applications and vast theoretical research developed on them.

Fast flight performance, agility, and ability to hover are the main advantages of a quadrotor. In order to improve these edges, many control methods are applied up to now. The mentioned control methods are exemplified as conventional control methods [7-8], nonlinear backstepping control [9-10], geometric tracking control [11], adaptive control [12], adaptive backstepping [13], sliding mode [14], robust adaptive control [15], discrete-time controllers [16-17]. In addition, in order to control the UAV system has been not attracted attention to the discrete-time controller designs according to continuous time controllers in the literature.

The backstepping control method is a nonlinear control method where the chattering effect within the controller has not existed. This can also be named as the main advantage over sliding mode control. The crucial issue of the backstepping method can also be mentioned as disturbance rejection and robustness. In case of disturbance and uncertainties within the system, these can be compensated by considering these issues in the controller design [18-19]. Since multi degrees of freedom actuators

*Corresponding Author:fatihadiguzel1@istanbul.edu.tr

Received: 31.12.2019 Published: 30.09.2020 
plays a vital role in the quadrotor realization and design, the backstepping control method can be shown as a suitable technique for multi degrees of freedom actuator controller design. The last but not least, the usage of the backstepping controller brings a total decrease of uncertainties together with state variables [20].

In order to overcome many difficult problems such as complex dynamic structure, high-order nonlinearities, and coupling phenomena in nonlinear systems, the backstepping method in the continuous-time domain or discrete-time domain has been also widely used [21-22]. However, in digital applications, discrete-time control designs stand out due to the applicability and performance features such as faster time response and rise time. This prefer is also valid for the nonlinear control approaches. By means of taking the mentioned advantages for the discrete-time controllers into account, and this study aims to develop and design a discrete-time backstepping controller to stabilize the height position and to maintain stabilize of the hover attitude in the quadrotor system. Note that the initial results of this study are represented in a conference paper [23].

In the following sections of this study, the dynamical quadrotor math model is introduced in continuous-time and discretized. Afterward, utilizing Forward-Euler approximation, the quadrotor dynamical model equations are discretized. In the next section, a nonlinear backstepping height and attitude controllers are obtained considering error dynamics in the discrete-time setting. A Lyapunov function is used to explain the stability of the developed subsystems for the height and attitude control. The last section illustrates the successful numerical simulations for the viability index of the backstepping height and attitude controllers in the discrete setting. The last but not the least, the developed proposed controller is compared to conventional PD for all control objectives.

\section{MATHEMATICAL MODEL OF THE QUADROTOR}

In Figure 1. the inertial body and earth frames of a conventional quadrotor for the math model are represented. On the figure, $B=(x, y, z)^{T}$ stands for body-fixed and $E=\left(e_{x}, e_{y}, e_{z}\right)^{T}$ is for earth frame. The following assumptions are made for the math model: The weight of the vehicle uniformly distributed along the body and all the propellers are rigid and mounted fixed to the axes. The gravity center and the body frame centers are the same. The applied forces to the system are proportional to the speed of each propeller.

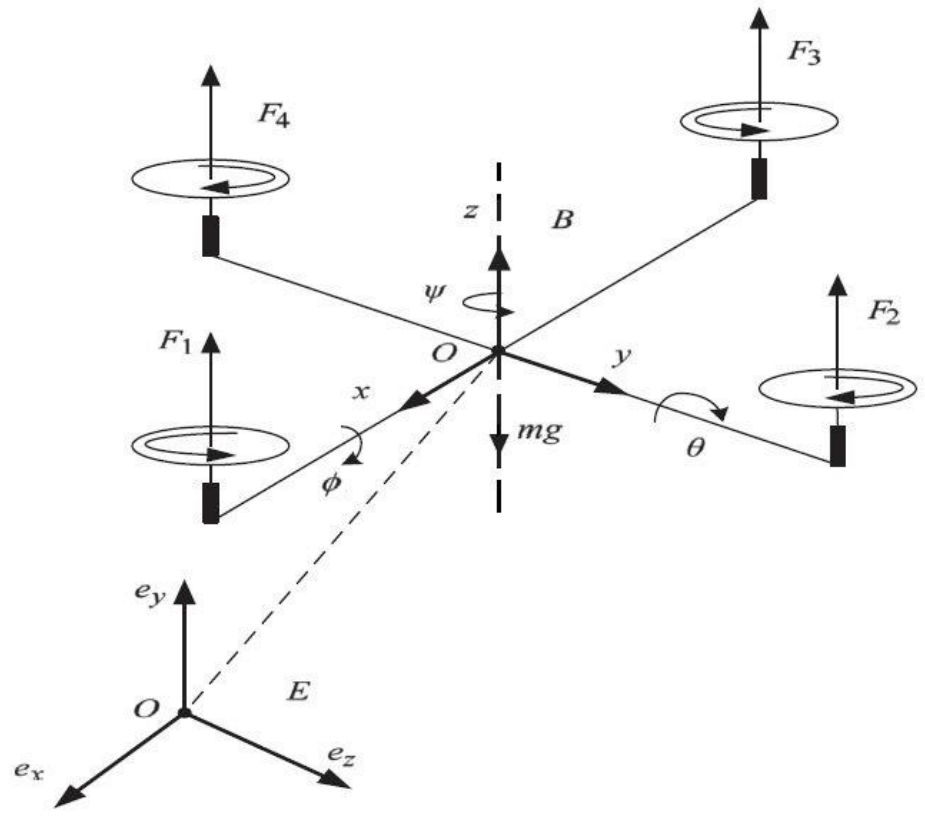

Figure 1. The body orientation Euler angles and earth frame of a conventional quadrotor 
Defining T: $\mathrm{E} \rightarrow \mathrm{B}$, the transformation matrix of the quadrotor from $[\phi, \theta, \psi]^{\prime}$ which symbolize the attitude angles, that are the roll, the pitch and yaw Euler angles, to $[p, q, r]^{\prime}$ which symbolize angular velocities of the quadrotor in the body-frame can be written as (1):

$$
\left[\begin{array}{l}
\mathrm{p} \\
\mathrm{q} \\
\mathrm{r}
\end{array}\right]=\left[\begin{array}{lll}
1 & 0 & -\mathrm{s}(\theta) \\
0 & \mathrm{c}(\phi) & \mathrm{s}(\phi) \mathrm{c}(\theta) \\
0 & -\mathrm{s}(\phi) & \mathrm{c}(\phi) \mathrm{c}(\theta)
\end{array}\right]\left[\begin{array}{l}
\dot{\phi} \\
\dot{\theta} \\
\dot{\psi}
\end{array}\right]
$$

where $s(*)$ and $c(*)$ stand for $\sin (*)$ and $\cos (*)$ for the simplicity, respectively. Euler angles $[\phi, \theta, \psi]$ used for this math model $[\phi, \theta, \psi]$ can be seen below

$$
\phi=\left(-\frac{\pi}{2}, \frac{\pi}{2}\right), \quad \theta=\left(-\frac{\pi}{2}, \frac{\pi}{2}\right), \quad \psi=(-\pi, \pi) .
$$

The whole dynamic model including translational $(x, y, z)$ and rotational $(\phi, \theta, \psi)$ dynamics can be written as below [24-25]

$$
\begin{aligned}
& \ddot{x}=\frac{1}{m}(c(\phi) s(\theta) c(\psi)+s(\phi) s(\psi)) u_{1}-\frac{K_{1} \dot{x}}{m} \\
& \ddot{y}=\frac{1}{m}\left(c(\phi) s(\theta) s(\psi)-s(\phi) c(\psi) u_{1}-\frac{K_{2} \dot{y}}{m}\right. \\
& \ddot{z}=\frac{1}{m}(c(\phi) c(\theta)) u_{1}-g-\frac{K_{3} \dot{z}}{m} \\
& \ddot{\phi}=\dot{\theta} \dot{\psi} \frac{I_{y}-I_{z}}{I_{x}}+\frac{I_{r}}{I_{x}} \dot{\theta} \Omega_{r}+\frac{1}{I_{x}} u_{2}-\frac{K_{4} l}{I_{x}} \dot{\phi} \\
& \ddot{\theta}=\dot{\phi} \dot{\psi} \frac{I_{z}-I_{x}}{I_{y}}+\frac{J_{r}}{I_{y}} \dot{\phi} \Omega_{r}+\frac{1}{I_{y}} u_{3}-\frac{K_{5} l}{I_{y}} \dot{\theta} \\
& \ddot{\psi}=\dot{\phi} \dot{\theta} \frac{I_{x}-I_{y}}{I_{z}}+\frac{1}{I_{z}} u_{4}-\frac{K_{6}}{I_{z}} \dot{\psi}
\end{aligned}
$$

Here, $\mathrm{x}, \mathrm{y}$ and $z$ are used for the positions for the quadrotor gravitational center, $\mathrm{l}$ and $\mathrm{m}$ are depicted as the length from the rotor center to the gravitational center, and the total mass. Thus, $g$ is depicted as well-known gravitational acceleration. $\mathrm{I}_{\mathrm{x}}, \mathrm{I}_{\mathrm{y}}$ and $\mathrm{I}_{\mathrm{z}}$ illustrates the inertias within the four rotor dynamic model, $\mathrm{K}_{\mathrm{i}},(\mathrm{i}=1, \ldots, 6)$ are the positive constant factors for the drag force, $\Omega_{\mathrm{r}}=\Omega_{1}-\Omega_{2}+\Omega_{3}+\Omega_{4}$, $\Omega_{\mathrm{j}},(\mathrm{j}=1, \ldots, 4)$ are used for the jth propeller speed, $\mathrm{r}$ represents the overall speed of propeller $\mathrm{j} . \mathrm{J}_{\mathrm{r}}$ is the inertia torque. $\mathrm{u}_{1}, \mathrm{u}_{2}, \mathrm{u}_{3}$ and $\mathrm{u}_{4}$ illustrate thrust force along the $\mathrm{z}$-axis, the roll reference, the pitch reference and the yaw reference, respectively. Moreover, the thrust that the system produces $F_{j}=b \Omega_{j}^{2}$ by all the rotors it has and $\mathrm{u}_{1}, \mathrm{u}_{2}, \mathrm{u}_{3}$ and $\mathrm{u}_{4}$ is determined as:

$$
\left[\begin{array}{l}
\mathrm{u}_{1} \\
\mathrm{u}_{2} \\
\mathrm{u}_{3} \\
\mathrm{u}_{4}
\end{array}\right]=\left[\begin{array}{llll}
1 & 1 & 1 & 1 \\
0 & -1 & 0 & 1 \\
-1 & 0 & 1 & 0 \\
-\frac{\mathrm{d}}{\mathrm{b}} & \frac{\mathrm{d}}{\mathrm{b}} & \frac{\mathrm{d}}{\mathrm{b}} & \frac{\mathrm{d}}{\mathrm{b}}
\end{array}\right]\left[\begin{array}{l}
\mathrm{F}_{1} \\
\mathrm{~F}_{2} \\
\mathrm{~F}_{3} \\
\mathrm{~F}_{4}
\end{array}\right]
$$

Here, the term $b$ is a factor also often named as thrust, and $d$ is the length from the mass center and the propeller axis. Lastly, $F_{j}$ is used for the applied control signals within the air vehicle. 


\section{THE PROCESS OF THE MATH MODEL DISCRETIZATION}

The math model discretization necessary for the backstepping controller design will be explained in this section. The discretized rotational and translational math model will be derived from the continuous-time dynamical math model equations. The nonlinear equation approximation solutions can be extracted via using various methods that are already existed in the literature. In this study the well-known Forward-Euler method is selected for this purpose. In order to begin designing the discrete-time backstepping height controller and the controller responsible for the angle of the attitude, the discretized height and attitude subsystem equations for the variables of the state are sufficient. These are $\mathrm{z}$ for position and roll, pitch, yaw angles, respectively. To start with state variable are given as below:

$$
\begin{array}{ll}
\mathrm{z}=\mathrm{x}_{1}, \quad \dot{\mathrm{z}}=\mathrm{x}_{2}, \quad \phi=\mathrm{x}_{3}, \quad \dot{\phi}=\mathrm{x}_{4} \\
\theta=\mathrm{x}_{5}, \quad \dot{\theta}=\mathrm{x}_{6}, \quad \psi=\mathrm{x}_{7}, \quad \dot{\psi}=\mathrm{x}_{8} .
\end{array}
$$

The forward -Euler approximation for the necessary discretized math mode is given as,

$$
\dot{x}_{i}=\frac{x_{i}^{+}-x_{i}}{T}, \quad i=\{1, \ldots, 8\} .
$$

Moreover, the first derivative of the (4-7), the discretized dynamics are given for each variable as,

$$
\begin{aligned}
& \mathrm{x}_{1}^{+}=\mathrm{x}_{1}+\mathrm{Tx}_{2} \\
& \mathrm{x}_{2}^{+}=\left(1-\frac{\mathrm{TK}_{3}}{\mathrm{~m}}\right) \mathrm{x}_{2}+\frac{\mathrm{T}}{\mathrm{m}}\left(\mathrm{c}\left(\mathrm{x}_{3}\right) \mathrm{c}\left(\mathrm{x}_{5}\right)\right) \mathrm{u}_{1}-\mathrm{Tg} \\
& \mathrm{x}_{3}^{+}=\mathrm{x}_{3}+\mathrm{Tx}_{4} \\
& \mathrm{x}_{4}^{+}=\left(1-\frac{\mathrm{TK}_{4} \mathrm{l}}{\mathrm{I}_{\mathrm{x}}}\right) \mathrm{x}_{4}+\mathrm{Tx}_{6} \mathrm{x}_{8} \frac{\mathrm{I}_{\mathrm{y}}-\mathrm{I}_{\mathrm{z}}}{\mathrm{I}_{\mathrm{x}}}+\frac{\mathrm{TJ}_{\mathrm{r}}}{\mathrm{I}_{\mathrm{x}}} \mathrm{x}_{6} \Omega_{\mathrm{r}}+\frac{\mathrm{Tl}}{\mathrm{I}_{\mathrm{x}}} \mathrm{u}_{2} \\
& \mathrm{x}_{5}^{+}=\mathrm{x}_{5}+\mathrm{Tx}_{5} \\
& \mathrm{x}_{6}^{+}=\left(1-\frac{\mathrm{TK}_{5} \mathrm{I}}{\mathrm{I}_{\mathrm{y}}}\right) \mathrm{x}_{6}+\mathrm{Tx}_{4} \mathrm{x}_{8} \frac{\mathrm{I}_{\mathrm{z}}-\mathrm{I}_{\mathrm{x}}}{\mathrm{I}_{\mathrm{y}}}+\frac{\mathrm{TJ} \mathrm{r}}{\mathrm{I}_{\mathrm{y}}} \mathrm{x}_{4} \Omega_{\mathrm{r}}+\frac{\mathrm{Tl}}{\mathrm{I}_{\mathrm{y}}} \mathrm{u}_{3} \\
& \mathrm{x}_{7}^{+}=\mathrm{x}_{7}+\mathrm{Tx}_{8} \\
& \mathrm{x}_{8}^{+}=\left(1-\frac{\mathrm{TK}_{8}}{\mathrm{I}_{\mathrm{z}}}\right) \mathrm{x}_{4}+\mathrm{Tx}_{4} \mathrm{x}_{6} \frac{\mathrm{I}_{\mathrm{x}}-\mathrm{I}_{\mathrm{y}}}{\mathrm{I}_{\mathrm{z}}}+\frac{\mathrm{T}}{\mathrm{I}_{\mathrm{z}}} \mathrm{u}_{4}
\end{aligned}
$$

where $\mathrm{x}_{\mathrm{i}}$ and $\mathrm{x}_{\mathrm{i}}^{+},(\mathrm{i}=1, \ldots, 8)$ is for $\mathrm{x}_{\mathrm{i}}(\mathrm{k})$ and $\mathrm{x}_{\mathrm{i}}(\mathrm{k}+1)$ respectively, the arguments are not taken into account to keep the simplicity. In the next sections, $x_{i}^{+j},(j=(1,2, \ldots)),(i=1, \ldots, 8)$ will be used for $x_{i}(k+j)$. Moreover, $T$ and $k=0,1,2, \ldots$ illustrates the sampling instants and the period. Since the math model is highly coupled and under-actuated structure, having nonlinear dynamics. For the sake of the stable operational flight this study proposes the backstepping control method for the control objectives.

\section{THE CONTROLLER DESIGN FOR BACKSTEPPING INTEGRAL METHOD IN DISCRETE TIME}

Here, within this part for the given trajectories discrete-time backstepping controllers for height and attitude subsystems have been recursively obtained in one structure according to desired trajectories, respectively. After obtaining the first-order difference equations of the continuous-time system, since discretized system dynamics relate to the height and the attitude of the quadrotor have in the lower triangular form, the backstepping control technic can be applied directly to the relevant part of the 
quadrotor system. The discrete-time backstepping controller design for height and attitude controllers starts with the derivation of the error dynamics. Thence, the height controller position error $(\mathbf{z})$ and the attitude controller $(\boldsymbol{\phi}, \boldsymbol{\theta}, \boldsymbol{\Psi})$ can be formed as:

$$
e_{i}=x_{i}-x_{i d}, \quad i=(1,3,5,7)
$$

The height velocity error $\left(\mathrm{e}_{1}\right)$ and the attitude angular velocity error subsystem $\left(\mathrm{e}_{3}, \mathrm{e}_{5}, e_{7}\right)$ can be given as

$$
e_{i+1}=x_{i+1}-x_{(i+1) d}, \quad i=(1,3,5,7) .
$$

Here, $\mathrm{x}_{\mathrm{id}}$ and $\mathrm{x}_{(\mathrm{i}+1) \mathrm{d}}$ stand for the planned trajectories for $\mathrm{x}_{\mathrm{i}}$ and $\mathrm{x}_{(\mathrm{i}+1)}$, respectively. In this section, notice that, design steps will be repeated for $\mathrm{i}=(1,3,5,7)$ to the state variables. After that, considering the equations (10) - (17),

$$
\begin{aligned}
& e_{i}^{+}=x_{i}^{+}-x_{i d}^{+} \\
& =x_{i}+T x_{i+1}-x_{i d}^{+} \\
& =e_{i+1}^{+}=x_{i+1}^{+}-x_{(i+1) d}^{+}
\end{aligned}
$$

can be obtained. After this step, $\mathrm{e}_{(\mathrm{i}+1)}^{+}$can be written as:

$$
\begin{aligned}
& \mathrm{e}_{2}^{+}=\left(1-\frac{\mathrm{TK}_{3}}{\mathrm{~m}}\right) \mathrm{x}_{2}+\frac{\mathrm{T}}{\mathrm{m}}\left(\mathrm{c}\left(\mathrm{x}_{3}\right) \mathrm{c}\left(\mathrm{x}_{5}\right)\right) \mathrm{u}_{1}-\mathrm{Tg}-\mathrm{x}_{2 \mathrm{~d}}^{+} \\
& \mathrm{e}_{4}^{+}=\left(1-\frac{\mathrm{TK}_{4} \mathrm{l}}{\mathrm{I}_{\mathrm{x}}}\right) \mathrm{x}_{4}+\mathrm{Tx}_{6} \mathrm{x}_{8} \frac{\mathrm{I}_{\mathrm{y}}-\mathrm{I}_{\mathrm{z}}}{\mathrm{I}_{\mathrm{x}}}+\frac{\mathrm{TJ} \mathrm{r}}{\mathrm{I}_{\mathrm{x}}} \mathrm{x}_{6} \Omega_{\mathrm{r}}+\frac{\mathrm{Tl}}{\mathrm{I}_{\mathrm{x}}} \mathrm{u}_{2}-\mathrm{x}_{4 \mathrm{~d}}^{+} \\
& \mathrm{e}_{6}^{+}=\left(1-\frac{\mathrm{TK}_{5} \mathrm{l}}{\mathrm{I}_{\mathrm{y}}}\right) \mathrm{x}_{6}+\mathrm{Tx}_{4} \mathrm{x}_{8} \frac{\mathrm{I}_{\mathrm{z}}-\mathrm{I}_{\mathrm{x}}}{\mathrm{I}_{\mathrm{y}}}+\frac{\mathrm{TJ}_{\mathrm{r}}}{\mathrm{I}_{\mathrm{y}}} \mathrm{x}_{4} \Omega_{\mathrm{r}}+\frac{\mathrm{Tl}}{\mathrm{I}_{\mathrm{y}}} \mathrm{u}_{3}-\mathrm{x}_{6 \mathrm{~d}}^{+} \\
& \mathrm{e}_{8}^{+}=\left(1-\frac{\mathrm{TK}_{6}}{\mathrm{~m}}\right) \mathrm{x}_{8}+\mathrm{Tx}_{4} \mathrm{x}_{6} \frac{\mathrm{I}_{\mathrm{x}}-\mathrm{I}_{\mathrm{y}}}{\mathrm{I}_{\mathrm{z}}}+\frac{\mathrm{T}}{\mathrm{I}_{\mathrm{z}}} \mathrm{u}_{4}-\mathrm{x}_{8 \mathrm{~d}}^{+} .
\end{aligned}
$$

Since the references of the height position and the Euler angles are selected as constant trajectories, hence $\mathrm{x}_{\mathrm{id}}=\mathrm{x}_{\mathrm{id}}^{+}$. Considering (21), the virtual control signal $\mathrm{x}_{\mathrm{i}+1}$ is designed as

$$
\mathrm{x}_{\mathrm{i}+1}=\frac{1}{\mathrm{~T}}\left(-\mathrm{x}_{\mathrm{i}}+\mathrm{x}_{\mathrm{id}}^{+}-\mathrm{k}_{\mathrm{i}} \mathrm{e}_{\mathrm{i}}\right)+\mathrm{e}_{\mathrm{i}+1}
$$

where $\mathrm{k}_{\mathrm{i}}$ is positive constant controller parameters. Moreover, the virtual signals are calculated with (18). Thence, the error equations (20) with the designing virtual signals can be rewritten as

$$
\mathrm{e}_{\mathrm{i}}^{+}=\mathrm{Te}_{\mathrm{i}+1}-\mathrm{k}_{\mathrm{i}} \mathrm{e}_{\mathrm{i}} \text {. }
$$

Then, considering (22), (23), (24) and (25), the control signal $\mathrm{u}_{1}, \mathrm{u}_{2}, \mathrm{u}_{3}$ and $\mathrm{u}_{4}$ are constructed as

$$
\begin{aligned}
& \mathrm{u}_{1}=\frac{\mathrm{m}}{\mathrm{Tc}\left(\mathrm{x}_{3}\right) \mathrm{c}\left(\mathrm{x}_{5}\right)}\left[-\left(1-\frac{\mathrm{K}_{3}}{\mathrm{~m}}\right) \mathrm{x}_{2}+\mathrm{g}+\mathrm{x}_{2 \mathrm{~d}}^{+}-\mathrm{k}_{2} \mathrm{e}_{2}\right] \\
& \mathrm{u}_{2}=\frac{\mathrm{I}_{\mathrm{x}}}{\mathrm{Tl}}\left[-\left(1-\frac{\mathrm{TK}_{4} \mathrm{l}}{\mathrm{I}_{\mathrm{x}}}\right) \mathrm{x}_{4}-\mathrm{Tx}_{6} \mathrm{x}_{8} \frac{\mathrm{I}_{\mathrm{y}}-\mathrm{I}_{\mathrm{z}}}{\mathrm{I}_{\mathrm{x}}}-\frac{\mathrm{TJ}_{\mathrm{r}}}{\mathrm{I}_{\mathrm{x}}} \mathrm{x}_{6} \Omega_{\mathrm{r}}+\mathrm{x}_{4 \mathrm{~d}}^{+}-\mathrm{k}_{4} \mathrm{e}_{4}\right] \\
& \mathrm{u}_{3}=\frac{\mathrm{I}_{\mathrm{y}}}{\mathrm{Tl}}\left[-\left(1-\frac{\mathrm{TK}_{5} \mathrm{l}}{\mathrm{I}_{\mathrm{y}}}\right) \mathrm{x}_{6}-\mathrm{Tx}_{4} \mathrm{x}_{8} \frac{\mathrm{I}_{\mathrm{z}}-\mathrm{I}_{\mathrm{x}}}{\mathrm{I}_{\mathrm{y}}}-\frac{\mathrm{TJ}_{\mathrm{r}}}{\mathrm{I}_{\mathrm{y}}} \mathrm{x}_{4} \Omega_{\mathrm{r}}+\mathrm{x}_{6 \mathrm{~d}}^{+}-\mathrm{k}_{6} \mathrm{e}_{6}\right] \\
& \mathrm{u}_{4}=\frac{\mathrm{I}_{\mathrm{z}}}{\mathrm{T}}\left[-\left(1-\frac{\mathrm{TK}_{6}}{\mathrm{~m}}\right) \mathrm{x}_{8}-\mathrm{Tx}_{4} \mathrm{x}_{6} \frac{\mathrm{I}_{\mathrm{x}}-\mathrm{I}_{\mathrm{y}}}{\mathrm{I}_{\mathrm{z}}}+\mathrm{x}_{8 \mathrm{~d}}^{+}-\mathrm{k}_{8} \mathrm{e}_{8}\right]
\end{aligned}
$$


where $\mathrm{k}_{\mathrm{i}+1}$ is positive constant controller coefficient. $\mathrm{x}_{(\mathrm{i}+1) \mathrm{d}}^{+}$is obtained by using (26) as in the following:

$$
\mathrm{x}_{(\mathrm{i}+1) \mathrm{d}}^{+}=\frac{1}{\mathrm{~T}}\left(-\mathrm{x}_{\mathrm{i}}^{+}+\mathrm{x}_{\mathrm{id}}^{+2}-\mathrm{k}_{\mathrm{i}} \mathrm{e}_{\mathrm{i}}^{+}\right)
$$

where $\mathrm{x}_{\mathrm{id}}^{+2}=\mathrm{x}_{\mathrm{id}}^{+}$. Additionally, the equation (21) becomes

$$
\mathrm{e}_{\mathrm{i}+1}^{+}=-\mathrm{k}_{\mathrm{i}+1} \mathrm{e}_{\mathrm{i}+1} \text {. }
$$

At this point, the asymptotic stability of subsystems that belong to quadrotor systems is established in the following section.

\section{STABILITY ANALYSIS}

In order to show the stability of height and attitude of the quadrotor in the discrete time for backstepping controller, the Lyapunov function is formed as $\mathbf{V}=\sum_{\mathbf{i}=\mathbf{1}}^{\mathbf{6}} \mathbf{e}_{\mathbf{i}}^{\mathbf{2}}$ for $\mathbf{i}=\mathbf{1}, \ldots, \mathbf{8}$. Here, the difference can be calculated as

$$
\begin{aligned}
& \Delta \mathrm{V}=\mathrm{V}^{+}-\mathrm{V} \\
& =\sum_{\mathrm{i}=1}^{6}\left(\mathrm{e}_{\mathrm{i}}^{+}\right)^{2}-\sum_{\mathrm{i}=1}^{6} \mathrm{e}_{\mathrm{i}}^{2}
\end{aligned}
$$

Substituting (26) and (32) within the equation (34), it can be reformulated as

$$
\Delta V=\left(T^{2}+k_{2}^{2}-1\right) e_{2}^{2}+\left(k_{1}^{2}-1\right) e_{1}^{2}+\left(k_{3}^{2}-1\right) e_{3}^{2}+\left(T^{2}+k_{4}^{2}-1\right) e_{4}^{2}+\left(k_{5}^{2}-\right.
$$

1) $\mathrm{e}_{5}^{2}+\left(\mathrm{k}_{7}^{2}-1\right) \mathrm{e}_{7}^{2}+\left(\mathrm{T}^{2}+\mathrm{k}_{6}^{2}-1\right) \mathrm{e}_{6}^{2}-2 \mathrm{Tk}_{1} \mathrm{e}_{1} \mathrm{e}_{2}+\left(\mathrm{T}^{2}+\mathrm{k}_{8}^{2}-1\right) \mathrm{e}_{8}^{2}-2 \mathrm{Tk}_{3} \mathrm{e}_{3} \mathrm{e}_{4}-2 \mathrm{Tk}_{5} \mathrm{e}_{5} \mathrm{e}_{6}-$ $2 \mathrm{Tk}_{7} \mathrm{e}_{7} \mathrm{e}_{8}$.

By utilizing Cauchy's inequality;

$$
\begin{aligned}
& -2 \mathrm{Tk}_{1} \mathrm{e}_{1} \mathrm{e}_{2} \leq \frac{4 \mathrm{~T}^{2} \mathrm{k}_{1}^{2} \mathrm{e}_{1}^{2}}{\epsilon}+\epsilon \mathrm{e}_{2}^{2} \\
& -2 \mathrm{Tk}_{3} \mathrm{e}_{3} \mathrm{e}_{4} \leq \frac{4 \mathrm{~T}^{2} \mathrm{k}_{3}^{2} \mathrm{e}_{3}^{2}}{\epsilon}+\epsilon \mathrm{e}_{4}^{2} \\
& -2 \mathrm{Tk}_{5} \mathrm{e}_{5} \mathrm{e}_{6} \leq \frac{4 \mathrm{~T}^{2} \mathrm{k}_{5}^{2} \mathrm{e}_{5}^{2}}{\epsilon}+\epsilon \mathrm{e}_{6}^{2} \\
& -2 \mathrm{Tk}_{7} \mathrm{e}_{7} \mathrm{e}_{8} \leq \frac{4 \mathrm{~T}^{2} \mathrm{k}_{7}^{2} \mathrm{e}_{7}^{2}}{\epsilon}+\epsilon \mathrm{e}_{8}^{2}
\end{aligned}
$$

can be obtained with $\epsilon>0$. Then, equation (35) becomes

$$
\begin{aligned}
& \Delta \mathrm{V}=\left(\mathrm{k}_{1}^{2}-1+\frac{4 \mathrm{~T}^{2} \mathrm{k}_{1}^{2}}{\epsilon}\right) \mathrm{e}_{1}^{2}+\left(\mathrm{T}^{2}+\mathrm{k}_{2}^{2}-1+\epsilon\right) \mathrm{e}_{2}^{2} \\
& +\left(\mathrm{k}_{3}^{2}-1+\frac{4 \mathrm{~T}^{2} \mathrm{k}_{3}^{2}}{\epsilon}\right) \mathrm{e}_{3}^{2}+\left(\mathrm{T}^{2}+\mathrm{k}_{4}^{2}-1+\epsilon\right) \mathrm{e}_{4}^{2} \\
& +\left(\mathrm{k}_{5}^{2}-1+\frac{4 \mathrm{~T}^{2} \mathrm{k}_{5}^{2}}{\epsilon}\right) \mathrm{e}_{5}^{2}+\left(\mathrm{T}^{2}+\mathrm{k}_{6}^{2}-1+\epsilon\right) \mathrm{e}_{6}^{2} \\
& +\left(\mathrm{k}_{7}^{2}-1+\frac{4 \mathrm{~T}^{2} \mathrm{k}_{7}^{2}}{\epsilon}\right) \mathrm{e}_{7}^{2}+\left(\mathrm{T}^{2}+\mathrm{k}_{8}^{2}-1+\epsilon\right) \mathrm{e}_{8}^{2} .
\end{aligned}
$$

The stability conditions 


$$
\begin{array}{ll}
\mathrm{k}_{1}^{2}-1+\frac{4 \mathrm{~T}^{2} \mathrm{k}_{1}^{2}}{\epsilon}<0, & \mathrm{~T}^{2}+\mathrm{k}_{2}^{2}-1+\epsilon<0 \\
\mathrm{k}_{3}^{2}-1+\frac{4 \mathrm{~T}^{2} \mathrm{k}_{3}^{2}}{\epsilon}<0, & \mathrm{~T}^{2}+\mathrm{k}_{4}^{2}-1+\epsilon<0 \\
\mathrm{k}_{5}^{2}-1+\frac{4 \mathrm{~T}^{2} \mathrm{k}_{5}^{2}}{\epsilon}<0, & \mathrm{~T}^{2}+\mathrm{k}_{6}^{2}-1+\epsilon<0 \\
\mathrm{k}_{7}^{2}-1+\frac{4 \mathrm{~T}^{2} \mathrm{k}_{7}^{2}}{\epsilon}<0, & \mathrm{~T}^{2}+\mathrm{k}_{8}^{2}-1+\epsilon<0 .
\end{array}
$$

can be obtained and thereby, $\left\|\mathrm{e}_{\mathrm{i}}^{2}\right\|,(\mathrm{i}=1, \ldots 8)$ for all $\mathrm{k}$, here is the error bounded. Hence, using Barbalat's lemma,

$$
\lim _{k \rightarrow \infty} e_{i}^{2}=0, \quad(i=1, \ldots 8)
$$

are satisfied. Notice that, the system angle errors disappear when (45) is fulfilled. Here, the aim of this study is confirmed.

\section{SIMULATON RESULTS}

In order to show the achievable and practice of the designed backstepping controller for the multirotor attitude subsystem and the height position, numerical simulations are provided. The controller performance for this application is compared with the PD controller that is one of the conventional control approaches. The numerical simulation is realized within MATLAB/Simulink environment. Here, the sampling period for the controller is chosen as $0.001 \boldsymbol{s}$.

Table 1. Model Parameters of UAV.

\begin{tabular}{ccc}
\hline Variables & Value & \multicolumn{1}{c}{ Units } \\
\hline $\mathrm{m}$ & 2.0 & $\mathrm{~kg}$ \\
$\mathrm{I}_{\mathrm{x}}=\mathrm{I}_{\mathrm{y}}$ & 1.25 & $\mathrm{Ns}^{2} / \mathrm{rad}$ \\
$\mathrm{I}_{\mathrm{z}}$ & 2.2 & $\mathrm{Ns}^{2} / \mathrm{rad}$ \\
$\mathrm{K}_{1}=\mathrm{K}_{2}=\mathrm{K}_{3}$ & 0.1 & $\mathrm{Ns} / \mathrm{m}$ \\
$\mathrm{K}_{4}=\mathrm{K}_{5}=\mathrm{K}_{6}$ & 0.012 & $\mathrm{Ns} / \mathrm{m}$ \\
$\mathrm{l}$ & 0.2 & $\mathrm{~m}$ \\
$\mathrm{~J}_{\mathrm{r}}$ & 1 & $\mathrm{Ns}^{2} / \mathrm{rad}$ \\
$\mathrm{b}$ & 2 & $\mathrm{Ns}^{2}$ \\
$\mathrm{~d}$ & 5 & $\mathrm{Nms}^{2}$ \\
$\mathrm{~g}$ & 9.8 & $\mathrm{~m} / \mathrm{s}^{2}$ \\
\hline
\end{tabular}

On Table 1 the model parameters for the system are given. The states are initially set to $\mathrm{z}$ position and the Euler angles: $\left[\mathrm{x}_{1}(0) ; \mathrm{x}_{3}(0) ; \mathrm{x}_{5}(0) ; \mathrm{x}_{7}(0)\right]=[0 ; 0 ; 0 ; 0]$ and the velocity of the $\mathrm{z}$ position and angular velocity of the Euler angles: $\left[\mathrm{x}_{2}(0) ; \mathrm{x}_{4}(0) ; \mathrm{x}_{6}(0) ; \mathrm{x}_{8}(0)\right]=[0 ; 0 ; 0 ; 0]$. The gains for the controller are chosen as $\mathrm{k}_{\mathrm{i}}=10$, $(\mathrm{i}=1, \ldots, 8)$. Besides, constant references trajectories are chosen as $\left[\mathrm{x}_{1 \mathrm{~d}} ; \mathrm{x}_{3 \mathrm{~d}} ; \mathrm{x}_{5 \mathrm{~d}} ; \mathrm{x}_{7 \mathrm{~d}}\right]=[5 ; \pi / 3 ; \pi / 3 ; \pi / 3]$ for the $\mathrm{z}$ position and the Euler angles, respectively.

The simulation results for height tracking and the attitude tracking are shown for $\mathrm{z}$ position and orientation angles in Figure 2. This figure illustrates the efficiency and validity of tracking reference values for the orientation angles and height. As the figure illustrates, the $\mathrm{z}$ position and the Euler angles reached effectively to the reference values. It is also shown in this figure that the convergence 
of the height position and the angle errors to zero is accomplished. The position $\mathrm{z}$ error and the errors of the angles changes can be seen in Figure 3. Moreover, the four control signals for the states are shown in Fig. 4. The simulations confirm the applicability of the proposed backstepping controllers which are designed in the discrete-time domain for a quadrotor system for height and orientation. Thence, the designed backstepping controller has been compared to the PD controller, and these results have been given in Figure 2. According to the simulation comparisons, the discrete-time backstepping controller has been going to the desired reference values with the more agile and faster performance for all design states.
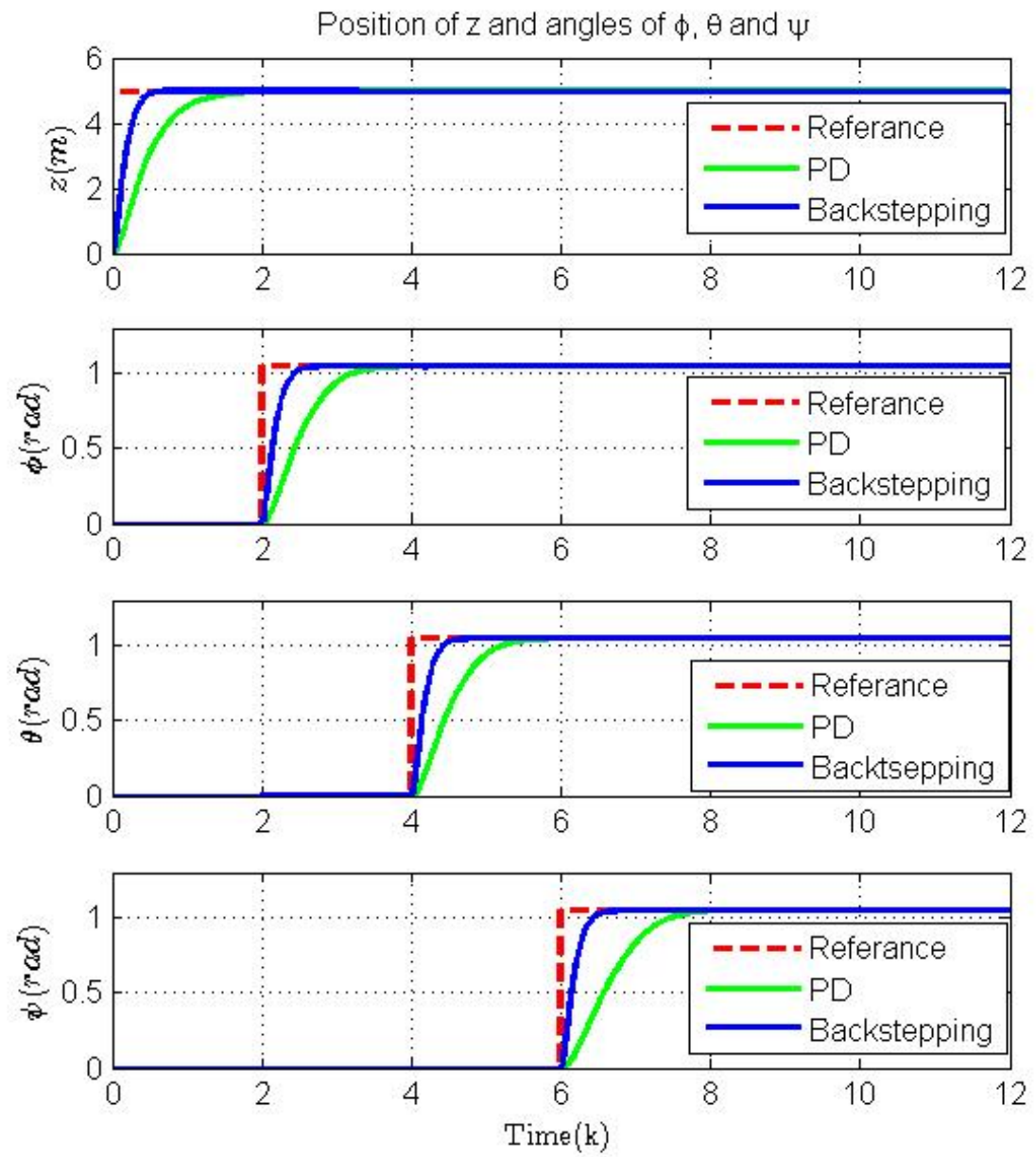

Figure 2. The quadrotor height (z) position and orientation angles roll, pitch and yaw $(\phi, \theta, \psi)$. 

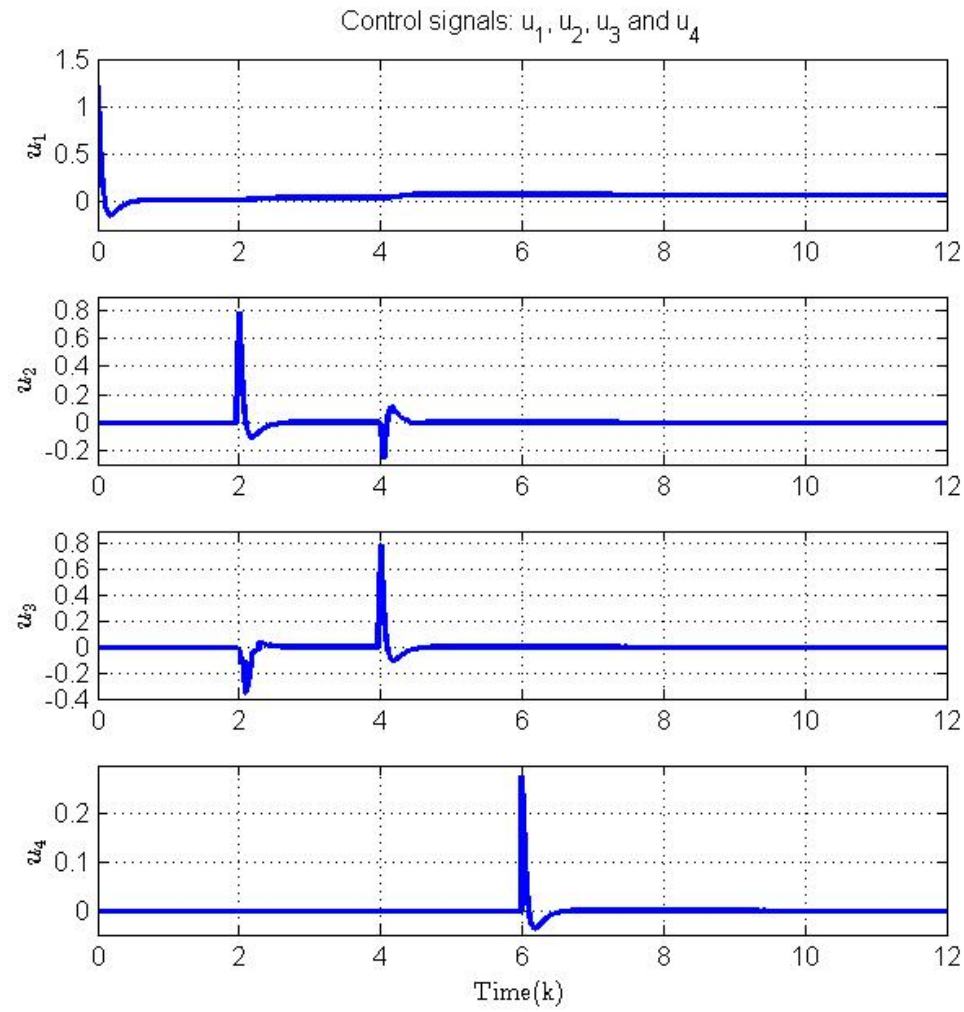

Figure 3. The angle errors $\left(e_{1}, e_{3}, e_{5}, e_{7}\right)$ for height position and orientation angles.
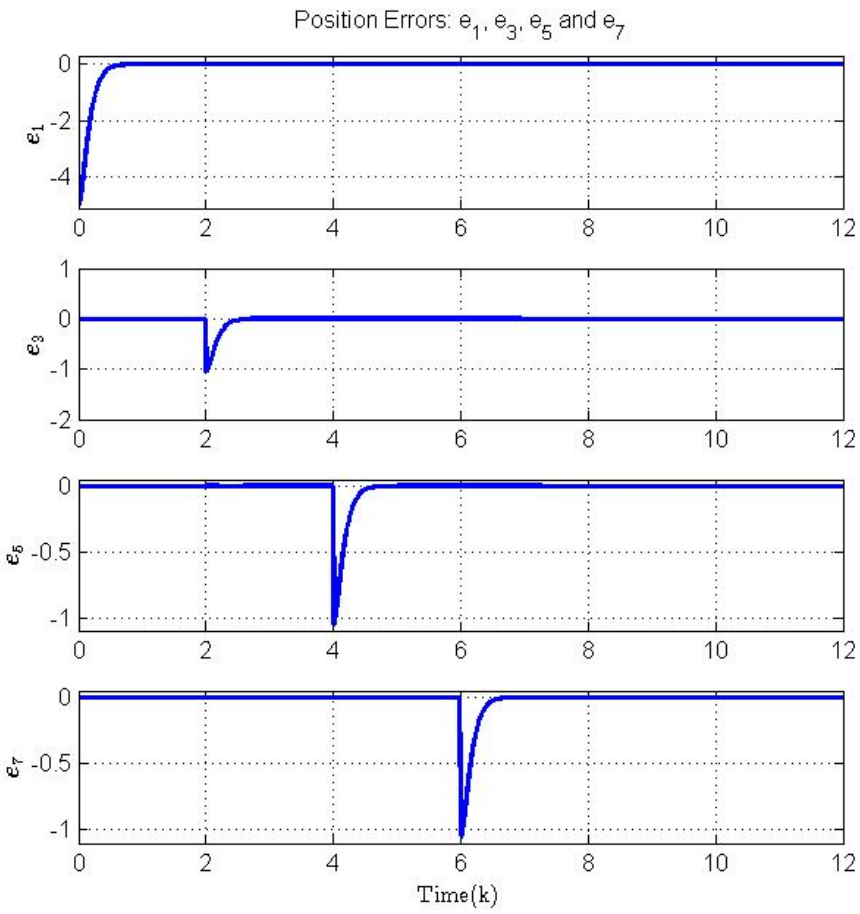

Figure 4. The inputs $\left(\mathrm{u}_{1}, \mathrm{u}_{2}, \mathrm{u}_{3}, \mathrm{u}_{4}\right)$ for the controller. 


\section{CONCLUSIONS}

In this paper, for the height and attitude tracking of a multirotor platform is realized via backstepping control in discrete-time. Height and attitude subsystems math model derivation is explained by utilizing the standard Euler approximation. The discrete-time backstepping controller is developed within a single structure for the constant reference trajectories. Thereafter, system dynamics height and attitude subsystems and their stability are shown in the sense of Lyapunov. Thus the convergence of the height position error and angle errors to zero are given. The last but not least, in order to examine the practice and efficiency of the developed controller, numerical simulations are presented. The simulation results show that the discrete nonlinear control method has a better tracking performance in comparison with conventional control PD.

\section{REFERENCES}

[1] Oltmanns S d'Oleire, Marzolff I, Peter K and Ries J. Unmanned aerial vehicle (uav) for monitoring soil erosion in morocco. Remote Sensing, 2012; vol. 4, no. 11, pp. 3390-3416.

[2] Nex F and Remondino F. Uav for 3d Mapping Applications: A Review. Applied Geomatics, 2014; vol. 6, no. 1, pp. 1-15.

[3] Girard AR, Howell AS and Hedrick JK. Border Patrol and Surveillance Missions using Multiple Unmanned Air Vehicles, in 2004 43rd IEEE Conference on Decision and Control (CDC)(IEEE Cat. No. 04CH37601), vol. 1. IEEE, 2004, pp. 620-625.

[4] Zhang C and Kovacs JM. The Application of Small Unmanned Aerial Systems for Precision Agriculture: A Review. Precision Agriculture, vol. 13, no. 6, pp. 693-712, 2012.

[5] Mahony R, Kumar V and Corke P. Multirotor Aerial Vehicles: Modeling, Estimation, and control of quadrotor. IEEE Robotics \& Automation Magazine, 2012; vol. 19, no. 3, pp. 20-32.

[6] Sujit P, Saripalli S and Sousa JB. Unmanned Aerial Vehicle Path Following: A survey and Analysis of Algorithms for Fixed-Wing Unmanned Aerial Vehicless. IEEE Control Systems Magazine, 2014; vol. 34, no. 1, pp. 42-59.

[7] Li J and Li Y. Dynamic Analysis and Pid Control for a Quadrotor, in 2011 IEEE International Conference on Mechatronics and Automation. IEEE, 2011, pp. 573-578.

[8] Hametner C, Mayr CH, Kozek M and Jakubek S. Pid Controller Design for Nonlinear Systems Represented by Discrete-Time Local Model Networks. International Journal of Control, 2013; vol. 86, no. 9, pp. 1453- 1466.

[9] Madani T and Benallegue A. Backstepping Control for A Quadrotor Helicopter, in 2006 IEEE/RSJ International Conference on Intelligent Robots and Systems. IEEE, 2006, pp.32553260 .

[10] Bouchoucha M, Seghour S, Osmani H, and Bouri M. Integral Backstepping for Attitude Tracking of a Quadrotor System. Elektronika ir Elektrotechnika, 2011; vol. 116, no. 10, pp. 7580 .

[11] Lee T, Leok M and McClamroch NH. Geometric tracking control of a quadrotor uav on SE (3), in 49th IEEE conference on decision and control (CDC). IEEE, 2010, pp. 5420-5425. 
[12] Dydek ZT, Annaswamy AM. and Lavretsky E. Adaptive Control of Quadrotor Uavs: A design Trade Study with Flight Evaluations, IEEE Transactions on Control Systems Technology, 2012; vol. 21, no. 4, pp. 1400- 1406.

[13] Tang S, Zhang L and Zheng Z. Adaptive Height and Attitude Control of Small-Scale Unmanned Helicopter, in 2013 25th Chinese Control and Decision Conference (CCDC). IEEE, 2013, pp. $1-6$.

[14] Xu R and Ozguner U. Sliding Mode Control of a Quadrotor Helicopter, in Proceedings of the 45th IEEE Conference on Decision and Control. IEEE, 2006, pp. 4957-4962.

[15] Nicol C, Macnab C and Ramirez-Serrano A. Robust Adaptive Control of a Quadrotor Helicopter, Mechatronics, 2011; vol. 21, no. 6, pp. 927-938.

[16] Lozano R, Sanchez A, Salazar-Cruz S and Fantoni I. Discrete-time stabilization of integrators in cascade: Real-Time Stabilization of a Minirotorcraft. International Journal of Control, 2008; vol. 81, no. 6, pp. 894-904.

[17] Xiong J-J and Zhang G. Discrete-Time Sliding Mode Control for a Quadrotor Uav. OptikInternational Journal for Light and Electron Optics, 2016; vol. 127, no. 8, pp. 3718-3722.

[18] Cabecinhas D, Cunha R and Silvestre C. A Nonlinear Quadrotor Trajectory Tracking Controller with Disturbance Rejection. Control Engineering Practice, 2014; vol. 26, pp. 1-10.

[19] Dou J, Kong X and Wen B. Altitude and attitude active disturbance rejection controller design of a quadrotor unmanned aerial vehicle," Proceedings of the Institution of Mechanical Engineers, Part G: Journal of Aerospace Engineering, 2017; vol. 231, no. 9, pp. 1732-1745.

[20] Krstic M, Kanellakopoulos I, Kokotovic PV et al., Nonlinear and Adaptive Control Design. Wiley New York, 1995, vol. 222.

[21] Khalil HK. Nonlinear Systems, Upper Saddle River, 2002.

[22] Tanasa V, Monaco S and Normand-Cyrot D. Backstepping Control Under Multi-Rate Sampling. IEEE Transactions on Automatic Control, 2015; vol. 61, no. 5, pp. 1208-1222.

[23] Adigüzel F and Mumcu TV. Discrete-Time Backstepping Attitude Control of a Quadrotor Uav, in 2019 International Artificial Intelligence and Data Processing Symposium (IDAP). IEEE, 2019, pp. 1-5.

[24] Alexis K, Nikolakopoulos G and Tzes A. Model Predictive Quadrotor Control: Attitude, Altitude and Position Experimental Studies. IET Control Theory \& Applications, 2012; vol. 6, no. 12 , pp. 1812-1827.

[25] Xu R and Özgüner Ü, Sliding Mode Control of A Class of Underactuated Systems, Automatica, 2008; vol. 44, no. 1, pp. 233-241. 